\title{
Angst in de stedelijke nacht
}

AUTEUR Irina van Aalst, Tim Schwanen \& Frank de Beer

FOTOGRAFIE Frank de Beer

In de schaduw van de nacht gebeuren dingen die het daglicht niet kunnen verdragen. Onveiligheid in de avonduren lijkt een toenemend probleem voor Nederlandse binnensteden. Maar wat maakt mensen bang? Is het de specifieke plek, de aanwezigheid van anderen of is het de duisternis?

Een bruisend nachtleven is belangrijk in de huidige concurrentiestrijd tussen steden. Hoewel stad en consumptie van oudsher met elkaar zijn verbonden, wordt er steeds meer belang gehecht aan een gevarieerd aanbod van theaters, restaurants, cafés en clubs. Dat is niet alleen goed voor de stedelijke economie, maar ook voor het imago van de stad. Veel bezoekers associëren de nachtelijke uren met avontuur, romantiek en feest. Anderen daarentegen, vrezen de confrontatie met dronken jongeren of zijn bang het slachtoffer te worden van geweld. Vaak wordt de dreiging van de stedelijke nacht gezocht in de bebouwde omgeving: de donkere stegen en tunneltjes, verlaten plekken en parken. Stedelijke beleidsmakers hanteren dan ook vaak een 'designing out of fear' strategie. Door ingrepen in de fysieke inrichting pogen ze overlast en criminaliteit te reduceren en gevoelens van veiligheid onder bezoekers te vergroten. Daarnaast plaatsen ze meer verlichting en camera's en hanteren ze een 'zero-tolerance' beleid bij overlast. Het is vooralsnog onduidelijk in hoeverre deze maatregelen effectief zijn en of mensen hun uitgaansgedrag laten beïnvloeden door gevoelens van (on)veiligheid. Waar, wanneer en waarom passen bezoekers hun gedrag aan? En maakt het daarbij uit wie je bent?

Dit artikel gaat over de mate waarin jongeren zich onveilig voelen in de openbare ruimte rondom uitgaansgelegenheden op het Caterplein in Apeldoorn en daarom hun gedrag aanpassen. Het is gebaseerd op twaalf diepte-interviews met studenten - zes mannen en zes vrouwen, allen blank, heteroseksueel en 18-25 jaar - die regelmatig het Caterplein bezoeken. Hoewel ze niet representatief zijn voor het totale uitgaanspubliek, geven de interviews een genuanceerd en gedetailleerd inzicht in de aard, oorzaken en consequenties van onveiligheidsgevoelens tijdens het uitgaan.

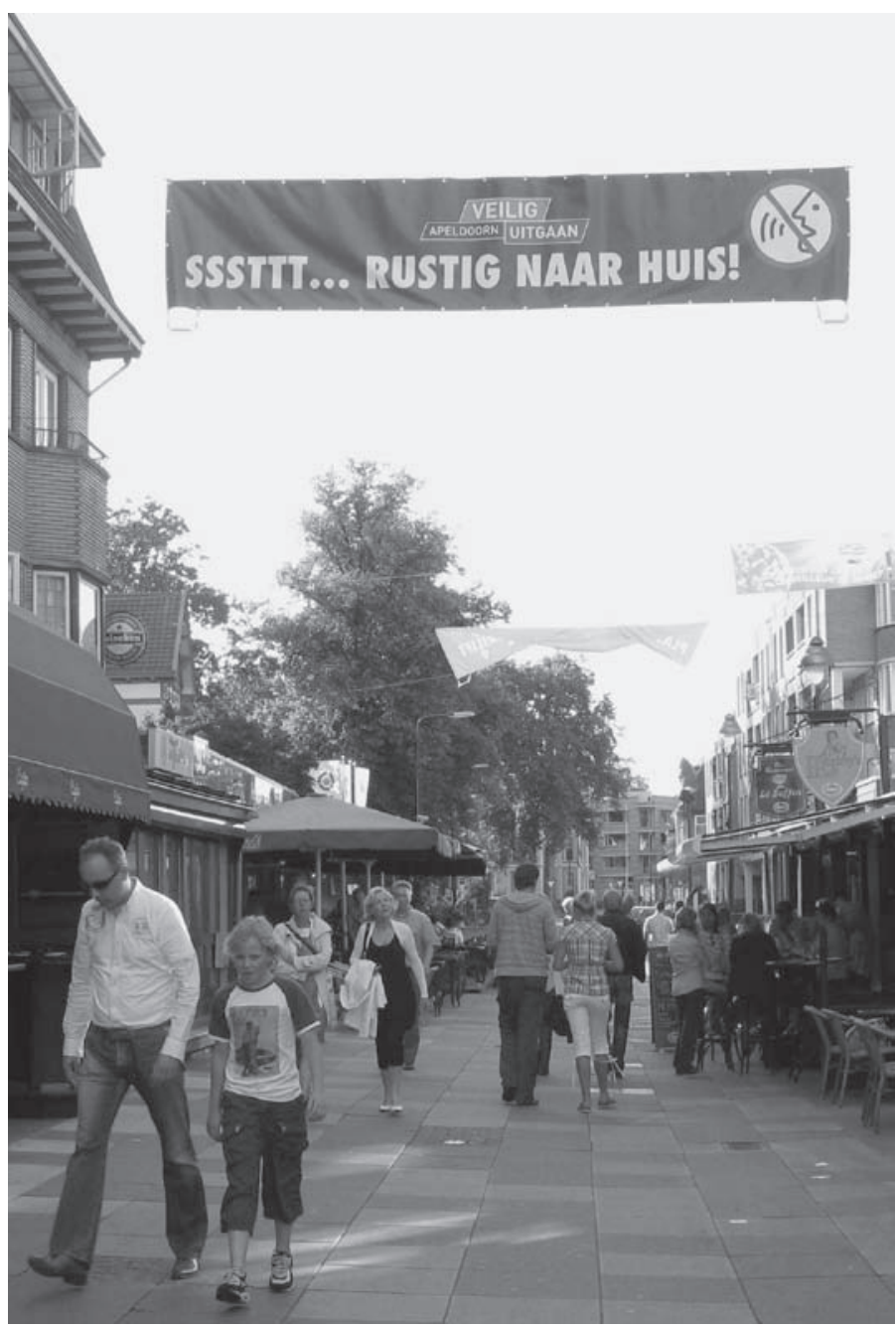




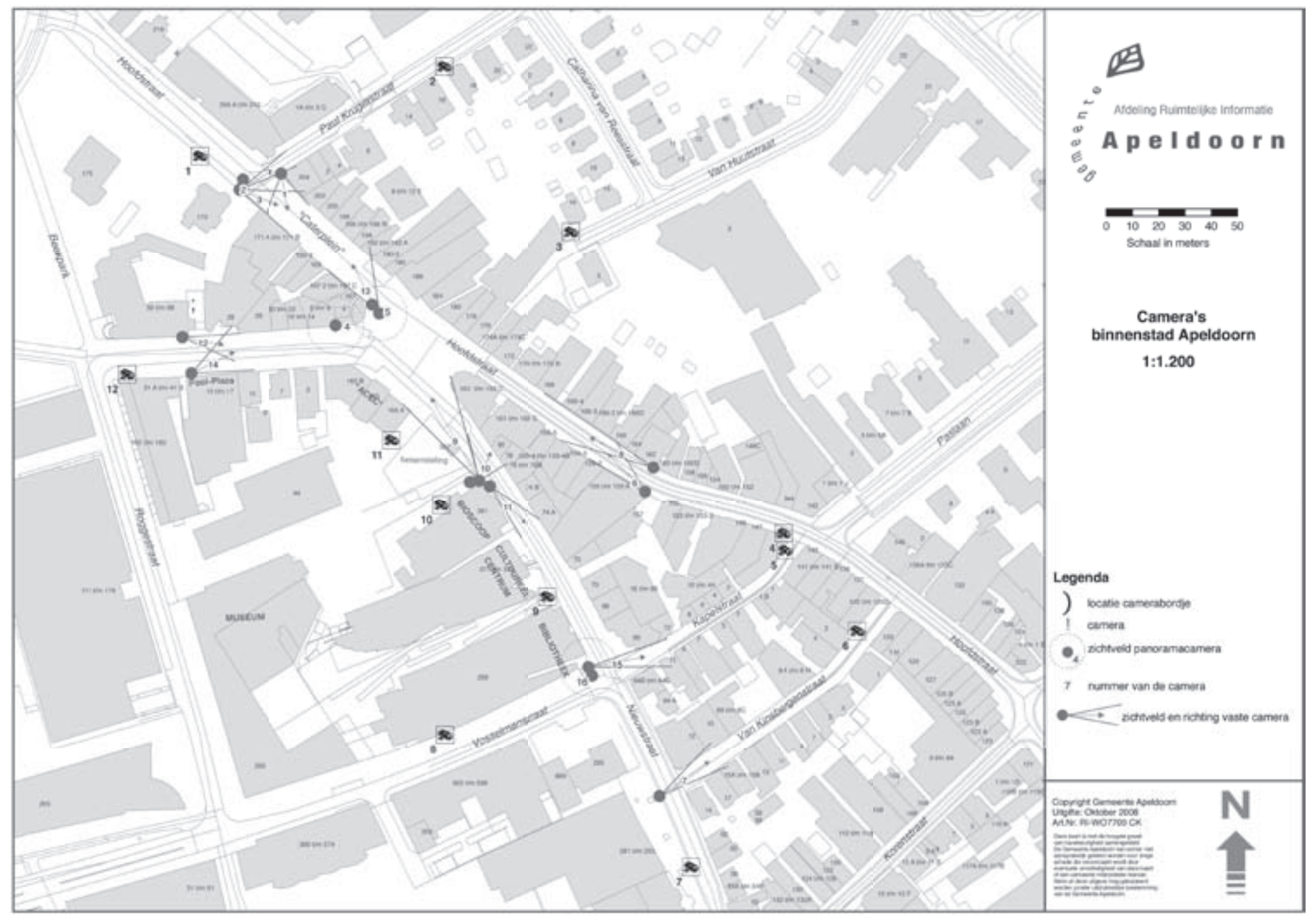

Locatie camera's Caterplein (Gemeente Apeldoorn, 2008)

\section{Maakbaarheid van veiligheid}

In Apeldoorn is het uitgaansgebied rondom het Caterplein in 25 jaar tijd uitgegroeid tot een horecagebied met regionale aantrekkingskracht. Na een aantal incidenten, die in 1997 de landelijke pers haalden, werd een actieplan opgesteld om de veiligheid te vergroten, de overlast te verminderen en het onderhoud van de openbare ruimte te verbeteren. Gemeente, politie, horeca-ondernemers en de wijkraadCentrum - verenigd in het Overleg Uitgaanscentrum Apeldoorn (OAU) - kwamen gezamenlijk met concrete maatregelen. Op basis van de 'Crime Prevention Through Environmental Design' (CPTED) principes, in Nederland bekend als 'Veilig Ontwerp en Beheer', kwam er meer toezicht. De politie-inzet werd op uitgaansavonden verdubbeld en de samenstelling veranderde. Politie te paard en hondenbrigades vormen inmiddels een gewoon beeld en worden door de meeste respondenten geaccepteerd als 'noodzakelijk kwaad' en een 'vanzelfsprekend onderdeel van een uitgaansavond'. Sommigen zijn negatiever en voelen een vorm van onbehagen. Meer blauw op straat zou ten koste gaan van de sfeer op het plein. De wijze waarop de politie zich presenteert, vormt hierbij een belangrijk aspect. De aanwezigheid van paarden en honden maakt dat ze zich afvragen of er gevaar dreigt. Agenten op een mountainbike worden daarentegen zeer gewaardeerd: ze zijn mobieler en stralen meer ontspanning uit.

Daarnaast is het uitgaansgebied voorzien van panoramacamera's. Het volledig in beeld krijgen van de openbare ruimte zou de pakkans ver- groten en de bezoekers het gevoel geven dat er iemand is die de situatie in de gaten houdt. Alhoewel de meeste respondenten de camera's positief beoordelen, hebben sommige vrouwen hun bedenkingen over de effectiviteit. Zo zegt Fleur: "Ik hecht meer waarde aan de politie. Ik heb niets aan een camera die daar hangt wanneer mij wat gebeurt. Misschien dat dan de dader wel achteraf gepakt kan worden, maar het kwaad is voor mij dan al geschied."

Ook de openbare ruimte is aangepakt: er zijn 'uriliften' - urinoirs die op gewenste tijden uit de grond 'gelift' kunnen worden - geplaatst en het plein is voorzien van calamiteitenverlichting. Dit zijn schijnwerpers die bij een incident ingeschakeld kunnen worden zodat hulpverleners een duidelijk beeld van de situatie krijgen en bezoekers sneller kalmeren. Verder is een aantal horecaspecifieke maatregelen getroffen, waaronder aanpassingen in de sluitingstijden van cafés. Zo hoopt de gemeente Apeldoorn de alcoholconsumptie te beïnvloeden en het aantal alcoholgerelateerde incidenten te reduceren. Daarnaast staat de aanpak van notoire overlastveroorzakers hoog op de agenda. Een deel van deze maatregelen voor het Caterplein is neergelegd in de Kwaliteitsmeter Veilig Uitgaan (KVU), een in 2005 door horecaondernemers, politie, gemeente en de wijkraad Centrum ondertekend convenant.

\section{Angst voor 'anderen'}

De respondenten vinden het totale design van het Caterplein belangrijk, maar een grotere rol is weggelegd voor de sociale aspecten van de 
stedelijke nacht. De aanwezigheid van mensen met 'afwijkend' gedrag, zoals wildplassers, luidruchtige groepen jongeren en drugsverslaafden, roept gevoelens op van kwetsbaarheid en onveiligheid. Deze 'anderen' kunnen je iets aandoen en alleen ben je een gemakkelijker mikpunt van agressie in een openbare ruimte vol met anderen. Dergelijke gevoelens worden intenser naarmate de avond vordert. Ze pieken tussen 03:00 en 04:00 uur, wanneer de meeste mensen naar huis gaan. Zo zegt Wendy: "Nou ja er zijn dan wel heel veel mensen die heel veel gedronken hebben en die dan vervelend worden." Chris wijst op de toename van groepen (jonge) jongens. "De sfeer draait dan gewoon om. (...) het zijn vooral de jonge gastjes die dingen aan het uitproberen zijn en die haantjesgedrag vertonen en die voor dat sfeertje zorgen, dus als je die weet te weren, dan ben je al een heel eind."

Mannen lijken vooral op hun hoede voor onbekende groepen jongens waarvan ze het gedrag slecht kunnen inschatten. De onvoorspelbaarheid geeft hen het gevoel de situatie minder onder controle te hebben, resulterend in angst voor (onverwachte) confrontaties. Het gaat om "het groepsgevoel tegenover mij als individu. Dat wanneer er iets gebeurt ik er waarschijnlijk niet ongeschonden uit zou komen. Sommige groepen zijn dreigender dan andere groepen. Je hebt gewoon bepaalde types mensen. Ik wil nu niet teveel vooroordelen geven, maar jongeren van het VMBO [voorbereidend middelbaar beroepsonderwijs] zijn daar wat anders in, wat meer impulsief dan anderen", aldus Guido (zelf hoog opgeleid). Negatieve stereotypering van specifieke groepen in de media en vriendenkring is een belangrijke factor in deze gevoelens. Vooral jongeren met een andere culturele achtergrond worden als bedreigend ervaren. Zo zegt Chris: "En dat is dus ook het probleem met die groep [Marokkanen en Molukkers], je weet niet hoe ze reageren. Dat zorgt er voor dat je redelijk machteloos bent op het moment dat er wat gebeurt. Wanneer die los gaan dan gaan ze ook compleet door het lint. Tenminste dat is het beeld dat ik er van heb." Ook Jesper voelt zich wat minder op zijn gemak bij een groep 'buitenlanders': "dan was ik waarschijnlijk zonder op of om te kijken rechtdoor gelopen. Vaak gebeurt er toch niks, maar je voelt je toch wat ongemakkelijk als zo'n groep daar staat te hangen. Er hoeft er maar eentje kwade zin te hebben en je hebt de hele groep om je heen staan."

Mannen lijken liever in een rustiger omgeving te vertoeven, met een goed overzicht over de ruimte waardoor ze minder snel in onverwachte situaties kunnen belanden. De vrouwelijke respondenten hebben een andere angst. Zij voelen zich vaak kwetsbaar ten opzichte van mannen en zijn bang voor (fysiek en verbaal) seksueel getint geweld. In tegenstelling tot de mannelijke respondenten vrezen zij groepen jongens minder dan individuen. Zo zegt Fleur: "juist een groep komt minder bedreigend over, omdat ik weet dat het wel bij roepen blijft enzo. Dat is toch anders dan wanneer een individu je achterna loopt of je op staat te wachten." Sanne denkt dat het "bij een grote groep meer een weddenschap is, meer stoer schreeuwen en wie de meeste meiden gek kan maken weet je wel." De vrouwelijke geïnterviewden ervaren de

\section{Er zijn duidelijke grenzen aan de maakbaarheid van de ste- delijke nacht.}

aanwezigheid van veel andere mensen positiever dan de mannelijke respondenten: het geeft de indruk van sociale controle en het idee dat anderen een helpende hand kunnen bieden, mocht er iets gebeuren.

\section{Gedragsstrategieën van jongeren}

Er zijn verschillende manieren waarop mensen gevoelens van angst in de stedelijke nacht kunnen reduceren. Een aantal daarvan kan als 'bescherming' worden betiteld. Zo kan iemand gebruik maken van een wapen in de breedste zin van het woord. Het gaat dan niet alleen om vuur- of steekwapens maar om alle voorwerpen die bewust en effectief ter verdediging kunnen worden gebruikt: fietssleutels, hangsloten, etcetera. Geen van onze respondenten blijkt 'wapens' te dragen wanneer zij uitgaan, maar dat wil niet zeggen dat men het bezit ervan volledig afkeurt. Er lijkt een bewuste afweging te worden gemaakt tussen enerzijds de wet overtreden en bijvoorbeeld pepperspray meenemen en anderzijds de wet respecteren met een sterker gevoel van onveiligheid als gevolg. Niet alleen de regelgeving, ook de opgedane ervaring speelt in deze een belangrijke rol. Guido, bijvoorbeeld, bereidt zich niet voor op wat er kan gebeuren: "omdat ik zelf nooit echt met dat soort zaken in aanraking ben gekomen. Ik ga meer met het idee van een gezellige avond naar het plein, dan dat ik het idee heb in elkaar geslagen te gaan worden."

Een andere beschermingsstrategie is het bewust in groepsverband naar de stad gaan. Dit heeft als voordeel dat plekken die anders angst oproepen, niet hoeven te worden vermeden. Deze strategie is vooral populair onder vrouwen. "Gewoon omdat het donker is en allemaal van die dronken lui die dingen aan het schreeuwen zijn. Ik probeer dan ook altijd samen met iemand naar huis te fietsen. Het is niet dat ik echt bang ben in m'n eentje, maar toch fiets ik altijd hard door mocht ik toch alleen zijn", aldus Lianne. Wanneer dit niet mogelijk is, dan kiezen veel vrouwen óf voor de auto - en dus het vermijden van specifieke situaties - óf voor hard doorfietsen. Vaak wordt bij de laatste optie de mobiele telefoon in de aanslag gehouden als extra beschermende maatregel. Zo zegt Petra "altijd als ik alleen fiets heb ik wel gewoon een mobiel bij de hand. Als er wat is dan kan ik meteen 112 bellen."

Een andere categorie strategieën is gericht op het vermijden van specifieke locaties, bepaalde personen, bijzondere tijdstippen of een combinatie ervan. Waar het beleid zich vooral richt op het Caterplein zelf, ervaren de meeste respondenten de straten en stegen eromheen juist als beangstigend. Vermijdingsstrategieën worden ook vaak ingegeven door de 'sociale constructie' van de nacht - de manier waarop deze wordt beschreven in de media en de verhalen (en waarschuwingen) van vrienden en familie van jongeren. De volgende reacties op de vraag welke situaties worden vermeden, illustreren beide punten. "Donkere steegjes, maar ik denk dat iedereen dat doet. Je hoort daar wel vaker gekke verhalen over, dat er dingen gebeuren en zo en in zo'n donker steegje ziet toch niemand anders wat er gebeurt, dus dan fiets of loop ik liever even om", aldus Harry. Michiel zegt: "Ja, misschien als er een grote groep allochtonen had gestaan dat ik zou denken; ik maak een ommetje."

Dat vermijdingsstrategieën een duidelijke temporele dimensie hebben, blijkt uit het feit dat de meeste mannelijke en vrouwelijke respondenten niet tot sluitingstijd rond het Caterplein blijven hangen. De redenen 
hiervoor lopen uiteen. "De sfeer is goed tot een uurtje of twee. Ja, je houdt het niet echt bij want je zit in de kroeg dus op het moment dat je naar huis gaat, loop je naar je fiets en dat is het. Maar op het moment dat je gaat kan je wel beter om 02:00 dan om 04:00 gaan. Ik ga niet bewust eerder weg hoor. Op het moment dat ik zou kunnen kiezen tussen 03:30 en 04:00, dan zou ik wel bewust eerder gaan, omdat je dan de massa voor bent", aldus Chris. "Nou ja ik ben daar niet zo heel consequent in, maar ik heb soms wel het idee van ik ga nu naar huis, want ik vind het een beetje grimmig worden. Ja, dat gevoel heb ik wel eens", zegt Michiel.

\section{Dreiging ligt in de bebouwde omgeving: donkere stegen, verlaten plekken en parken.}

Hoewel ze gebaseerd zijn op een klein aantal interviews, zijn onze uitkomsten wel degelijk beleidsrelevant. Wij pleiten voor een herbezinning op het fysiek determinisme van 'veilig ontwerp en beheer', beheersing door technologie (cameratoezicht) en het repressief handelen van de overheid. Ten eerste zijn er duidelijke grenzen aan de maakbaarheid van de stedelijke nacht. Immers, een uitgaansgebied is geen statisch decor maar een assemblage of dynamisch netwerk waarin mensen en fysieke elementen nauw zijn verweven en samen een atmosfeer creëren die voortdurend verandert. Ten tweede is het beleid momenteel selectief in ruimtelijk opzicht. Niet alleen het uitgaansgebied zelf, maar ook de straten en stegen eromheen hebben effect op de (on) veiligheidservaring en beleving van het uitgaansgebied zelf. Ten derde zou de overheid - gezien de rol van stereotypische vooroordelen over 'anderen' - een proces van bewustwording ten aanzien van de effecten van stigmatisering onder media, institutionele actoren én bezoekers op gang moeten brengen. Ten vierde bestaat dé uitgaansbezoeker niet. $\mathrm{Er}$ moet rekening worden gehouden met verschillen in sociale identiteiten en persoonlijke geschiedenissen. Daarbij hoort ook dat beleid moet erkennen dat mensen de aanwezigheid van anderen soms als plezierig ervaren, bijvoorbeeld omdat er zo sociale controle ontstaat, en soms als bedreigend, omdat anderen ook agressief kunnen worden in de openbare ruimte. Dit geldt eveneens voor fysieke elementen. De één voelt zich onveilig in een slecht verlichte straat waar potentiële daders ongestoord hun gang kunnen gaan, terwijl de ander zich juist onveilig voelt in een goed verlichte omgeving omdat hij/zij daar zelf zichtbaarder - en dus een helderder doelwit - is.

Om bovengenoemde punten in concrete maatregelen om te zetten lijkt een meer participatieve vorm van beleid maken zinvol: niet 'voor' maar 'met' bezoekers als sociaal heterogene belanghebbenden. Op deze manier vermoeden wij dat het subtiele samenspel van fysieke elementen en aanwezige personen, het spanningsveld tussen 'anderen'- het uitgaanspubliek maar ook ordehandhavers - en de eigen identiteit, én de diversiteit van bezoekers die uitgaansgebieden kenmerken beter tot haar recht komt.
Irina van Aalst (i.vanaalst@geo.uu.nl) is als stadsgeograaf verbonden aan het Urban and Regional Research Centre, Universiteit Utrecht. Tim Schwanen is als onderzoeker werkzaam bij de School of Geography and the Environment, University of Oxford en het Urban and Regional Research Centre, Universiteit Utrecht. Frank de Beer is afgestudeerd stadsgeograaf en werkzaam bij BMC.

\section{Literatuurselectie}

Boomkens, R. (2008) De continuiteit van de plek; Van de maakbare naar de mondiale stad. Open 15, pp. 6-17

Brownlow, A. (2005) A geography of men's fear. Geoforum 36, pp. 581-592. Chatterton, P. \& R. Hollands (2003) Producing Nightlife in the New Urban Entertainment Economy: Corporatization, Branding and Market Segmentation. International Journal of Urban and Regional Research 27, nr. 2, pp. $361-385$ Day, K., C. Stump \& D. Carreon (2003) Confrontation and loss of control: Masculinity and men's fear in public space. Journal of Environmental Psychology 23, pp. 311-322.

Gemeente Apeldoorn (2008) Camera's binnenstad Apeldoorn (kaart). Afdeling Ruimtelijke Informatie, Apeldoorn

Koskela, H. \& R. Pain (2000) Revisiting fear and place: women's fear of attack and the built environment. Geoforum 31, pp. 269-280.

Koskela, H. (2002) Video Surveillance, Gender and the Safety of Public Urban Space: "Peeping Tom" Goes Hi-Tech? Urban Geography 23, nr. 3, pp. 257-278.

Pain, R. (2000) Place, social relations and the fear of crime: a review. Progress in Human Geography 24, nr. 3, pp. 365-387.

Vries, de C. (1998) Politie pikt niets meer op het Karateplein. De Volkskrant, 27 februari 1998

Schuilenburg, M. (2008) Het ontregelend doorzicht van assemblages; Een andere blik op het veiligheidsvraagstuk. Open 15, pp. 18-35. 